\title{
The time-course of morphological constraints: Evidence from eye- movements during reading
}

Article

Accepted Version

Cunnings, I. and Clahsen, H. (2007) The time-course of morphological constraints: Evidence from eye-movements during reading. Cognition, 104 (3). pp. 476-494. ISSN 00100277 doi: https://doi.org/10.1016/j.cognition.2006.07.010 Available at https://centaur.reading.ac.uk/34384/

It is advisable to refer to the publisher's version if you intend to cite from the work. See Guidance on citing.

Published version at: http://www.sciencedirect.com/science/article/pii/S0010027706001624

To link to this article DOI: http://dx.doi.org/10.1016/j.cognition.2006.07.010

Publisher: Elsevier

All outputs in CentAUR are protected by Intellectual Property Rights law, including copyright law. Copyright and IPR is retained by the creators or other copyright holders. Terms and conditions for use of this material are defined in the End User Agreement.

www.reading.ac.uk/centaur

\section{CentAUR}


Central Archive at the University of Reading

Reading's research outputs online 
Published in: Cognition 104: 467-494.

\title{
The Time-Course of Morphological Constraints: \\ Evidence from Eye-Movements During Reading
}

\author{
Ian Cunnings Harald Clahsen
}

(University of Essex)

(C) 2007 Elsevier B.V.

Corresponding Author:

Harald Clahsen

Department of Linguistics

University of Essex

Colchester, C04 3SQ, UK

email: harald@essex.ac.uk

Tel: +44/1206/87-2228

Fax: $+44 / 1206 / 87-2198$ 


\begin{abstract}
Lexical compounds in English are constrained in that the non-head noun can be an irregular but not a regular plural (e.g. mice eater vs. *rats eater), a contrast that has been argued to derive from a morphological constraint on modifiers inside compounds. In addition, bare nouns are preferred over plural forms inside compounds (e.g. mouse eater vs. mice eater), a contrast that has been ascribed to the semantics of compounds. Measuring eyemovements during reading, this study examined how morphological and semantic information become available over time during the processing of a compound. We found that the morphological constraint affected both early and late eye-movement measures, whereas the semantic constraint for singular non-heads only affected late measures of processing. These results indicate that morphological information becomes available earlier than semantic information during the processing of compounds.
\end{abstract}




\section{Introduction}

The question of how different sources of information become available over time during on-line language comprehension has received much attention in psycholinguistic research. Answers to this question bear on the more general controversy between serial and interactive models of language processing, with the former type of model consistent with the view that early stages of language comprehension are only affected by structural (morpho-syntactic) information (e.g. Frazier \& Clifton 1996, Binder, Duffy \& Rayner 2001) and the latter type consistent with the view that language comprehension at any given point in time is also affected by non-structural (lexical, semantic, discourse-level) information (e.g. Altmann, Garnham \& Dennis 1992, Thornton, Gil \& MacDonald 1998).

Time-course issues also arise for the processing of morphologically complex words. Consider, for example, the kinds of non-head elements (or modifiers) that appear in lexical compounds in English. The non-head noun can be an irregular but not a regular plural (e.g. mice eater vs. *rats eater), a contrast that has been argued to derive from a morphological constraint on how inflectional processes may feed lexical compounding (see e.g. Kiparsky 1982). Moreover, bare nouns are preferred over plural forms inside compounds (e.g. mouse eater vs. mice eater), a contrast that has been ascribed to the semantics of compounds (Haskell, MacDonald, \& Seidenberg, 2003). Given these constraints, the question arises as to at which point in time they affect the processing of a compound. Does the morphological constraint become available earlier in time than the semantic one, or are both constraints employed in parallel? Previous studies on modifier constraints for compounds have largely relied on off-line acceptability judgments (see e.g. Haskell et al., 2003) and off-line elicited production tasks (see e.g. Gordon 1985); but see Buck-Gengler, Menn \& Healy (2004) for a version of Gordon's (1985) production task in which production latencies were additionally measured. Against this background, the purpose of the present study was to demonstrate 
how processes involved in the real-time comprehension of compounds, specifically the role of morphological and semantic constraints, can be studied experimentally. We examined the time-course of these constraints by recording participants' eye-movements during reading, a technique that provides a rich source of data on moment-to-moment language processing (Rayner 1998).

Several recent studies have relied on eye-movement measures to study the processing of compounds. A number of studies have examined bimorphemic compounds in Finnish, which were found to be affected by the length of a compound (Bertram \& Hyönä 2003, Hyönä, Bertram \& Pollatsek 2004), orthographic/phonological cues (Bertram, Pollatsek \& Hyönä 2004), the semantic transparency of a compound (Pollatsek \& Hyönä 2005), and frequency (Hyönä \& Pollatsek 1998, Pollatsek, Hyönä \& Bertram 2000). These studies revealed, for example, that short compounds are more likely to be recognized in a holistic manner than long compounds and that phonological cues such as the rules of vowel harmony in Finnish aid the parsing of long compounds into their constituents, particularly in cases in which the initial fixation was located relatively far away from the constituent boundary. With respect to frequency, Hyönä \& Pollatsek (1998) found that both the frequency of a compound as a whole and the frequencies of its constituents affect reading times, a finding that Andrews, Miller and Rayner (2004) have since replicated for English. The importance of the second, head constituent in English compounds is demonstrated by Juhasz, Starr, Inhoff and Placke (2003) who found, in a series of naming, lexical decision and eye-movement experiments, that compound processing is more effective if the second constituent is high in frequency, suggesting that the full compound is accessed via the head constituent. Finally, Juhasz, Inhoff and Rayner (2005) also adopted lexical decision and eye-movement methodologies to examine the role of interword spaces in compound processing in English (e.g. frontdoor Vs. front door). They argued that spatial separation facilitates access to individual compound 
constituents, whilst spatial unification favours access to full compound meaning. These findings replicate earlier observations by Inhoff, Radach and Heller (2000), who investigated the role of interword spaces in compound processing in German. Although these studies have provided important insights into the on-line processing of compounds, the time-course of constraints on modifiers inside compounds and the question of how morphological and semantic information become available over time during the processing of a compound have not yet been investigated.

The constraints on modifiers inside compounds have been examined in a number of previous off-line rating and production studies. Results from acceptability judgment tasks (Haskell et al. 2003) have shown that compounds containing singular nouns as non-heads are preferred over plural forms inside compounds. This contrast can be interpreted as an effect of a semantic constraint against compound-internal modifiers with plural NUMBER semantics. Typically, the non-head of a compound refers to a kind, not an individual. A mouse-eater eats mice in general, not a particular kind or number of mouse. In English, a singular noun form is identical to a bare nominal stem and is therefore more acceptable inside a compound than a plural form, which is explicitly marked for NUMBER.

An additional contrast is between regular and irregular plurals as non-heads of lexical compounds. Regular plurals inside compounds are judged considerably worse than irregular plurals, and in elicited production, young children, adolescents, and adult native speakers include significantly more irregular plurals than regular ones inside compounds (Gordon 1985, van der Lely \& Christian 2000, Murphy 2000). There are several linguistic implementations to capture this contrast. Kiparsky (1982) argued that regular inflection is strictly ordered after other morphological processes such as irregular inflection, derivation, and compounding so that regular inflectional affixes are prevented from appearing inside compounds. Aronoff (1976) and Di Sciullo and Williams (1987) claim that lexical 
compounding joins stems rather than words, and that irregular plurals are stems while regular plurals are words. Similarly, Borer (1988) posits that compounding takes stored words out of the lexicon and that irregular plurals (but not regular ones) are listed in the lexicon; see also Pinker (1999) who mentions the dissociation between regular and irregular plurals inside compounds as evidence for his distinction between rule-based (regular) inflection and associatively-based (irregular) inflection. The idea that is common to all these accounts is that the use of plural forms inside lexical compounds is morphologically constrained, i.e. determined by a distinction among kinds of morphological forms.

Two recent studies, however, (Buck-Gengler et al. 2004, Haskell et al. 2003) have questioned the morphological characterization of the compounding facts and proposed alternative non-morphological accounts. Buck-Gengler et al. argued that singular non-heads are generally preferred inside compounds and that the differences seen in elicited production tasks between regular and irregular plural non-heads are due to the higher surface form (= orthographic/phonological) overlap between a regular plural and its corresponding singular form (e.g. rats vs. rat) than between an irregular plural and its corresponding singular form (e.g. mice vs. mouse). Buck-Gengler et al. presented evidence from two elicited production experiments in which they found that, when presented with a probe that contained a plural form (e.g. 'Someone who catches mice/rats is a ...'), subjects produced significantly more irregular plurals inside compounds than regular ones. However, when probed with a singular noun (e.g. Someone who catches a mouse/rat is a ...'), subjects unanimously produced singulars inside compounds. Additionally, Buck-Gengler et al. obtained production latencies for the elicited compound forms. They found that when subjects were probed with an irregular plural form they took significantly longer to produce compounds containing singular non-heads than when they were probed with the corresponding singular form. For regular plurals, however, there was no such contrast. Buck-Gengler et al. took these findings 
as indicating that singular non-heads are preferred inside compounds and that singular forms are more easily accessible from a regular plural (due to their surface overlap) than they are from an irregular plural form.

There are a number of problems with this account. Firstly, the pattern of results obtained by Buck-Gengler et al. leaves open the possibility that the relative ease of accessing rat from rats is due to the morphological structure of a regular plural, rather than to orthographic or phonological overlap between the two forms. Assuming that regular (but not irregular) plurals are concatenative forms ([[rat+[s]], see e.g. Pinker 1999), a regular plural probe will be decomposed into stem+affix leading to direct activation of the stem. An irregular plural probe, however, will only indirectly activate its corresponding stem. Thus, Buck-Gengler et al.'s results are perfectly explainable in morphological terms. Secondly, elicited production data on plurals inside compounds in German (see Clahsen 1999 for review) revealed the same contrast between regular and irregular plurals as seen in English, i.e. regular (but not irregular) plurals tend to be omitted from inside compounds, despite the fact that many irregular plurals of German exhibit the same degree of surface form overlap to the corresponding singular form as regular plurals do. Compare, for example, the regular plural Autos 'cars' and its corresponding singular form (Auto) to the irregular plural Bauern 'farmers' and its singular form (Bauer). These plural forms exhibit the same degree of surface form overlap, but in German compounds, Bauern is a perfectly legal non-head, whereas Autos is banned from inside compounds. Contrasts such as this one are hard to explain in terms of surface form overlap. Thirdly, Buck-Gengler et al.'s account is specific to the elicited production task and does not apply to results from other tasks. Consider, for example, the finding from acceptability judgment tasks on plurals inside compounds (Haskell et al. 2003) that regular plural non-heads are dispreferred over irregular ones in compounds, a surprising finding if accessibility to the singular form was the decisive factor. 
Moreover, Haskell et al. found significantly more omissions of regular plurals inside compounds than irregular plurals in an analysis of the Brown corpus of written and spoken English. These findings indicate that speakers of English consistently omit more regular than irregular plurals inside compounds, even when they are not directly prompted to produce compounds under experimental conditions. For these reasons, we remain unconvinced by Buck-Gengler et al.’s account.

Another alternative non-morphological account is proposed by Haskell et al. (2003). They argued that the contrast between regular and irregular plurals inside compounds is the result of a phonological constraint according to which non-heads inside compounds should not have the phonological structure of a typical regular plural form; for example, they tend not to have codas ending in $s$ or $z$. This constraint is said to apply in tandem with the semantic constraint mentioned above resulting in different degrees of acceptability for a compound depending on the extent to which a given non-head element violates the typical properties of non-heads inside compounds. Haskell et al.'s evidence for a separate phonological constraint comes from the finding that bifurcate pluralia tantum nouns, such as pliers rack and tweezers box, which phonologically resemble regular plurals but are semantically singular, are only marginally acceptable inside compounds.

However, the use of bifurcate pluralia tantum nouns to assess the potential effect of nonhead phonology on compound acceptability is problematic, for a number of reasons. Evidence from verb attraction errors suggests that the marginal acceptability of bifurcate pluralia tantum nouns as non-heads inside compounds may not be due to their phonology. Attraction errors are speech errors in which speakers mistakenly select the morpho-syntactic features of the most recent noun phrase to agree with the verb. In experimental tasks designed to elicit such errors ('the trap for the rats...'), subjects were found to produce significantly more attraction errors when the most recent noun phrase was a plural form (e.g. 
'the rats') than when it was a singular form (Bock \& Eberhard 1993). Interestingly, Bock, Eberhard, Cutting, Meyer and Schriefers (2001) found that bifurcate pluralia tantum nouns caused subjects to produce significantly more attraction errors than corresponding singular nouns. Furthermore, bifurcate pluralia tantum nouns are often reduced inside compounds (one speaks of a trouser-press and listeners of contemporary popular music are likely to have heard of the band called the Scissor Sisters). In contrast, non-bifurcate pluralia tantum nouns are much less likely to be reduced (e.g. news reader, clothes hanger). Indeed, Senghas, Kim and Pinker (under review) found that subjects rated non-bifurcate pluralia tantum nouns as fully acceptable inside compounds.

These findings indicate that bifurcate pluralia tantum nouns might have a morphological structure parallel to that of regular plurals (e.g. $[[$ plier $]+[\mathrm{s}]$ ). Thus, it is possible to account for their marginal acceptability inside compounds in morphological, rather than phonological, terms. Whilst this provides an alternative explanation for the marginal acceptability of bifurcate pluralia tantum nouns as non-heads inside compounds, the points raised above seriously question the use of such nouns to assess the independent effects of phonology on compound acceptability.

More convincing evidence for a phonological constraint on compound formation as envisaged by Haskell et al. would come from the acceptability of compounds containing non-head nouns which are semantically and morphologically singular, but which nonetheless phonologically resemble regular plurals. Nouns of this type (e.g. tax, fox, hose, rose) do indeed exist in English, and Haskell et al. (2003: 143) specifically predicted that 'the phonological constraint should cause such words to be somewhat less acceptable as modifiers as other singulars'. In contrast to this prediction, however, numerous compounds are attested in the language which contain such nouns in non-head position (e.g. tax relief, fox hunter, hosepipe, rose garden). Furthermore, Berent, Pinker, Ghavami and Murphy 
(under review) found that subjects rated such compounds (e.g. fox chaser Vs. wolf chaser) as being fully acceptable.

Taken together, these findings not only cast doubt on Haskell et al.'s use of bifurcate pluralia tantum nouns to asses the independent effect of non-head phonology on compound acceptability, but also show that s/z-final phonology in a non-head does not render a compound unacceptable. Even though the nature of speakers' dislike of regular plurals in compounds remains a controversial issue, for the reasons mentioned above, we believe that it is hard to explain in purely phonological terms and maintain that the plurals-in-compounds effect is due to a morphological constraint against regular plurals inside compounds.

Although constraints on modifiers inside compounds have been intensively studied by morphologists and in offline experiments, their role in on-line processing is unknown. We can think of two models of the time course of these constraints. One is a structure-first account according to which initial stages of processing are purely structure-driven and nonstructural information (e.g. semantic and contextual cues) only affects later stages. This would be compatible with the view that language comprehension involves a sequence of stages and that the computation of morpho-syntactic information precedes the computation of semantic and pragmatic information (e.g. Frazier \& Fodor 1978, Rayner, Carlson \& Frazier 1983, McElree \& Griffith 1998, Frazier \& Clifton 1996). Applying this to modifiers inside compounds, the morphological constraint against regular plurals should have an immediate effect on processing, whilst the semantic constraint against irregular plurals should only affect later stages.

An alternative possibility is that the morphological and semantic constraints on nonheads inside compounds apply in parallel and that effects of these constraints are seen at both early and late stages of processing. This would fit in with constraint-satisfaction theories of sentence processing in which 'all relevant information sources are extracted and 
used the moment they are received as input' (Spivey, Fitneva, Tabor \& Ajmani 2002; 208). The parallel-constraints view of compound processing would be supported by demonstrating that both the semantic and the morphological constraint affect the processing of compounds equally early. However, although constraint-satisfaction models claim that all relevant constraints are immediately used, this does not necessarily mean that all relevant information sources will become available at the same time. With respect to compound processing, this allows for the possibility that morphological information may become available earlier than semantic information. If this is the case, the predictions of a constraint-satisfaction model of compound processing would be similar to those of the structure-first models mentioned above. Moreover, different constraints may have different relative strengths in an implemented multiple-constraints model. If, for example, the ban on regular plurals inside compounds has relatively more weight than the semantic constraint, then this may lead to a relative delay of the semantic constraint in processing. Under these circumstances, the predictions for the time-course of compound processing again would be similar to those of structure-first models. These additional possibilities can only be tested in an implemented constraint-satisfaction model of compound processing, which is currently not available.

The present paper reports results from two experiments investigating constraints on nonheads inside compounds. Experiment 1 was an acceptability judgment task to assess the role of morphological and semantic constraints in an offline task, and Experiment 2 measured eye movements during reading, to examine the time course of these constraints.

\section{Experiment 1}

Participants rated a series of compounds containing irregular plural, regular plural and singular non-head nouns. Following the results of previous studies (Haskell et al. 2003, Senghas et al. under review), we expected a gradual pattern of responses, with compounds containing singular non-head nouns yielding high acceptability scores, followed by 
compounds containing irregular plural non-heads, with compounds containing regular plurals eliciting the lowest scores.

\section{Method}

Participants

20 native English speakers (12 males, mean age 21.8) from south-east England voluntarily participated in Experiment 1.

\section{Materials}

Experimental items consisted of 54 novel synthetic compounds divided into three conditions. Nine irregular plural nouns, nine regular plural nouns and nine singular nouns were selected to appear as the non-heads of the 54 compounds. These were matched for length in letters, number of syllables and frequency, based on counts from the CELEX Lexical Database (Baayen, Piepenbrock \& van Rijn 1993). Given that the recognition of irregular plural forms appears to be mainly affected by word-form frequency and that of regular plurals by lemma/stem frequency (see e.g. Sonnenstuhl \& Huth 2002), we calculated word-form frequencies for the irregular plural items and matched these to the lemma frequencies of the regular plural items and singulars. A one-way ANOVA revealed no differences between any of the conditions, for any of the three matched variables (all Fs $<1$ ). Appendix A contains information on the length and the frequencies of all the non-head nouns used. These non-head nouns were each combined with two deverbal head nouns to create 54 experimental compounds (18 per condition), with the same head noun appearing in each condition (e.g. oxen/owls/hawk breeder, oxen/owls/hawk seller). A full list of non-head and head-noun combinations is provided in Appendix B. 
In addition to the experimental items, 50 filler items were constructed to prevent participants from developing any response strategies. These filler compounds were constructed to offer a range of variability on the acceptability scale, and contained a variety of different types of non-head and head nouns (e.g. news reader/clothes hanger/thunders storm).

All experimental and filler compounds appeared within short one-sentence contexts (e.g. Sally is the RAVEN FEEDER at the local zoo). Compounds always appeared in bold capital letters to ensure their salience within the context sentences.

\section{Procedure}

The 54 experimental items were pseudo-randomized with the 50 fillers, such that no two experimental items from the same condition appeared adjacent to each other. As each participant saw each experimental non-head noun twice (with a different head noun), two lists were created which were identical bar a reversal in the ordering of the experimental items. Participants were instructed to read each context sentence, and to rate the acceptability of the compound word only, on a scale from 1 (highly unacceptable) to 7 (fully acceptable).

\section{Results}

Mean acceptability ratings (and standard deviations) are shown in Table 1.

\section{//TABLE 1 HERE//}

A one-way ANOVA yielded a significant main effect of non-head type $\left(F_{1}(2,38)=\right.$ 64.34, $\left.\mathrm{p}<.001 ; F_{2}(2,51)=49.21, \mathrm{p}<.001\right)$, and subsequent pairwise comparisons revealed significant differences between each of the three conditions. Compounds containing singular 
non-heads were rated significantly more acceptable than compounds containing regular plurals $\left(t_{1}(19)=9.28, \mathrm{p}<.001 ; t_{2}(34)=11.88, \mathrm{p}<.001\right)$. Compounds containing irregular plurals were also rated significantly more acceptable than compounds containing regular plurals $\left(t_{1}(19)=6.66, \mathrm{p}<.001 ; t_{2}(34)=4.20, \mathrm{p}<.001\right)$, but significantly less acceptable than compounds containing singulars $\left(t_{1}(19)=6.50, \mathrm{p}<.001 ; t_{2}(34)=4.98, \mathrm{p}<.001\right)$.

These results confirm previous findings from acceptability judgment tasks indicating a three-way distinction between the different types of non-head noun. Both regular and irregular plurals are less acceptable inside compounds than singulars, whilst regular plurals are also less acceptable than irregular plurals. These results can be interpreted as a result of two constraints of compound formation - a semantic preference for non-heads to be singular, and an additional morphological constraint against regularly inflected plurals.

\section{Experiment 2}

This experiment investigates the time course of constraints on modifiers inside compounds. Participants read a series of short paragraphs containing the compounds from Experiment 1, whilst their eye movements were monitored. Structure-first models of language comprehension claim that grammatical information is computed before semantic and pragmatic information. From these models, we would expect that violations of the morphological constraint should lead to increased reading times from the earliest possible measures, whereas the semantic constraint should only affect later stages of processing. If, on the other hand, we find that both the semantic and the morphological constraint affect the processing of compounds equally early, then this would falsify the structure-first account and would be in line with a parallel-constraints models in which both constraints are used in tandem during compound comprehension. 
Method

Participants

28 native English speakers (10 males, mean age 23.7) with normal or corrected to normal vision from the University of Essex student community were paid to participate in Experiment 2, none of whom participated in Experiment 1.

\section{Materials}

The 54 experimental compounds tested in Experiment 1 were also used in Experiment 2. A series of two-sentence context paragraphs were constructed within which the compounds were embedded. Each context paragraph started with a sentence which always took up exactly one line on screen and that introduced a proper name. The second sentence always included one of the critical compound items, and was identical between conditions, bar the non-head noun. The critical compounds always appeared in postverbal position preceded by the definite determiner the and followed by a PP. The compounds' head nouns were all singular forms. An example from each condition is shown in (1):

\section{(1) Irregular plural non-head:}

Zoe has had itchy hair recently, but can't find her shampoo that will solve the problem. She has been looking for the lice remover since before 10 o'clock this morning.

Regular plural non-head:

Sam has an insecticide to kill the pests that have ruined her flowers, but she can't find it. She has been looking for the slugs remover since before 10 o'clock this morning. Singular non-head:

Kim can't find the special shampoo that'll help her itchy dog in any of the shops in town. She has been looking for the flea remover since before 10 o'clock this morning. 
80 filler texts were also constructed, 15 of which were structurally analogous to the experimental items, but contained simple nouns instead of compounds in the second sentence, whilst the remaining 65 filler texts comprised a variety of different kinds of syntactic construction. The experimental and filler items were pseudo-randomized, and two presentation lists were constructed in the same way as in Experiment 1.

\section{Procedure}

Participants were instructed to read the sentences silently at their normal reading rate, and press a button once completed. To ensure that participants paid attention to the meanings of the sentences, content questions requiring a yes/no push-button response were randomly displayed on screen, after approximately $20 \%$ of trials. Participants answered the content questions with a mean accuracy of $91.8 \%$ (SD 7.22).

Eye movements were recorded using the head-mounted EYELINK II system. Stimuli were presented on a screen $80 \mathrm{~cm}$ from the participants' eyes. At this viewing distance, one character onscreen subtended approximately one degree of visual angle. The eye-tracker records participants' eye movements via two cameras mounted on a headband at a sample rate of $500 \mathrm{~Hz}$, with spatial accuracy better than 0.5 degrees. Participants' head movements are automatically compensated for via a third camera mounted in the center of the headband, which tracks the position of four LEDs mounted on the corners of the computer screen. While viewing was binocular, eye movements were recorded from the right eye only.

An experimental session began with the setting up and calibration of the eye-tracking equipment on a nine-point grid. Prior to the presentation of each trial, calibration was checked via presentation of a drift correction marker towards the center-left of the screen, above the first word of the trial to be displayed. Participants were instructed to fixate upon 
this marker and press a button to view the next trial. If necessary, any drift in the headset was automatically corrected before presentation of the next trial. Before the experiment started, ten practice trials were presented to familiarize participants with the experimental procedure. The entire experiment lasted approximately 40 minutes.

\section{Data analysis}

Previous eye-movement experiments have indicated the importance of the head constituent in English compounds (Juhasz et al. 2003). Moreover, the head noun is the first element in the sentence at which one would expect to see effects of the various types of nonheads inside compounds. The target word for the main analyses of reading times was therefore the head noun of the compound (plus half a letter space either side).

Several reading time measures were calculated to provide a rich source of information regarding the time-course of processing of the target word. First fixation duration refers to the duration of the first fixation within a target region, whilst gaze duration is calculated by summing the duration of all fixations, starting with the first fixation when the eyes first enter a region from the left, up until the eyes first leave that region, either to the left or the right. Both of these measures are believed to be indexes of early stages of processing that accompany and directly follow lexical access. The third measure calculated was regression path duration. This measure is calculated by summing the duration of all fixations, starting with the first fixation when a region is first entered from the left, up until but not including the first fixation when the target region is first exited to the right. As this measure includes the duration of any regressive fixations out of the target region, regression path durations are generally longer than the other first-pass measures described above, and can be seen to index slightly later stages of processing, perhaps those related to the integration of the material in the current target region with the preceding text (Sturt 2003, Rayner, Warren, Juhasz \& 
Liversedge 2004). The fourth reading time measure calculated was rereading time. This measure is calculated by summing the duration of all refixations within a target region, after it has been exited to either the left or right for the first time. As this measure does not include the initial time spent viewing a region, it is believed to reflect later, second-pass stages of processing. The fifth measure calculated was total viewing time, which is the sum of all fixations within a region. This provides a general index of processing load, which takes into account both early and later stages of processing. Taken together, these measures represent a continuum from early to late stages of processing. If any of the compounding constraints influence early stages of processing, this should appear in the eye-movement record as increased reading times in the earliest measures mentioned above (first-fixation duration and gaze duration). Any differences between conditions that appear in the later measures would be evidence for constraints affecting later stages of processing.

Additional analyses were performed on the first-pass reading times of the non-heads of the compounds to examine whether, due to parafoveal processing of the head noun, effects of the experimental manipulations could already be seen for the first-pass reading times of the non-head nouns. To examine potential effects of the experimental manipulations on reading the text following the target word, we calculated the duration of the first fixation upon leaving the head noun after its first pass. This measure can be seen as an index of any additional spill-over processing caused by the text in the target region after it has been exited for the first time.

All measures were calculated contingent on a region gaining a progressive first fixation during its first-pass. Trials in which a region was initially skipped were treated as missing data. For rereading time, trials in which a region did not receive any subsequent refixations following the first-pass were treated as contributing a rereading time of zero to the calculation of averages. Fixations shorter than 50ms that were within one degree of another 
fixation were merged together. All other fixations shorter than 50ms were discarded before any further analysis, as little information is extracted during such short fixations (Rayner \& Pollatsek 1989). $1.4 \%$ of the critical trials (evenly distributed across conditions) were also removed due to tracker loss, or in cases in which the compound was fixated before reading of the second sentence had begun.

\section{Results}

Consider first the results for the target word, the head noun of the compounds. The head noun received a first-pass fixation in $85 \%$ of trials in the irregular plural condition, $85.2 \%$ of trials in the regular plural condition and $82.7 \%$ of trials in the singular condition. This amounted to a total first-pass fixation probability of $84.4 \%$, with no significant differences between conditions $\left(F_{1}(2,54)<1, \mathrm{p}=.449 ; F_{2}(2,51)<1, \mathrm{p}=.614\right)$. Condition means for the five reading time measures calculated for this region can be seen in Table 2 .

\section{//TABLE 2 HERE //}

A one-way ANOVA revealed a significant main effect of non-head type on the first fixation duration of the head noun $\left(F_{1}(2,54)=11.52, \mathrm{p}<.001 ; F_{2}(2,51)=3.87, \mathrm{p}=.007\right)$. Subsequent pairwise comparisons revealed that the $243 \mathrm{~ms}$ first fixation duration for head nouns of compounds containing regular plurals was significantly longer than both the $227 \mathrm{~ms}$ first fixation duration for head nouns of compounds containing irregular plurals $\left(t_{1}(27)=\right.$ 2.95, $\left.\mathrm{p}=.007 ; t_{2}(34)=1.94, \mathrm{p}=.061\right)$ and the $221 \mathrm{~ms}$ first fixation duration for head nouns of compounds containing singular non-heads $\left(t_{1}(27)=4.37, \mathrm{p}<.001 ; t_{2}(34)=2.56, \mathrm{p}=\right.$ .015). In contrast, the difference between the first fixation duration for head nouns of compounds containing irregular plurals in comparison to those containing singular non-heads 
(227ms and 221ms respectively) was not significant $\left(t_{1}(27)=1.58, \mathrm{p}=.127 ; t_{2}(34)<1, \mathrm{p}=\right.$ $.449)$.

The same pattern of results was obtained for gaze duration. A one-way ANOVA revealed a significant main effect of non-head type $\left(F_{1}(2,54)=17.63, \mathrm{p}<.001 ; F_{2}(2,51)=\right.$ $5.94, \mathrm{p}=.005$ ), and subsequent pairwise comparisons showed that the $279 \mathrm{~ms}$ gaze duration for head nouns of compounds containing regular plurals was significantly longer than both the 250ms gaze duration for head nouns of compounds containing irregular plurals $\left(t_{1}(27)=\right.$ 3.99, $\left.\mathrm{p}<.001 ; t_{2}(34)=2.87, \mathrm{p}=.007\right)$, and the $244 \mathrm{~ms}$ gaze duration for head nouns of compounds containing singular non-heads $\left(t_{1}(27)=5.14, \mathrm{p}<.001 ; t_{2}(34)=2.97, \mathrm{p}=.005\right)$. Moreover, the difference between the gaze duration of head nouns of compounds containing irregular plural non-heads in comparison to those containing singular non-heads (250ms and 244ms respectively) was not significant $\left(t_{1}(27)=1.32, \mathrm{p}=.197 ; t_{2}(34)<1, \mathrm{p}=.644\right)$.

Analysis of the regression path duration also revealed a significant main effect of nonhead type $\left(F_{1}(2,54)=11.97, \mathrm{p}<.001 ; F_{2}(2,51)=7.76, \mathrm{p}=.001\right)$. The 362ms regression path duration for head nouns of compounds containing regular plurals was significantly longer than both the 325ms regression path duration for head nouns of compounds containing irregular plural non-heads $\left(t_{1}(27)=2.68, \mathrm{p}=.012 ; t_{2}(34)=2.32, \mathrm{p}=.026\right)$ and the 291ms regression path duration for head nouns of compounds containing singular non-heads $\left(t_{1}(27)=4.89, \mathrm{p}<.001 ; t_{2}(34)=3.62, \mathrm{p}=.001\right)$. In contrast to the other two first-pass measures mentioned above (first fixation duration and gaze duration), the 325ms regression path duration for head nouns of compounds containing irregular plural non-heads was also significantly longer than the 291ms regression path duration for head nouns of compounds containing singulars $\left(t_{1}(27)=2.24, \mathrm{p}=.034 ; t_{2}(34)=1.80, \mathrm{p}=.080\right)$. The longer regression path duration for the two plural conditions in comparison to the singular condition indicates 
that subjects regressed out of the head noun region more often in these conditions than in the singular non-head condition.

The analysis of the rereading time data again revealed a significant main effect of nonhead type $\left(F_{1}(2,54)=4.18, \mathrm{p}=.020 ; F_{2}(2,51)=3.18, \mathrm{p}=.050\right)$. Pairwise comparisons revealed that rereading time was longer for head nouns of compounds containing regular plurals $(60 \mathrm{~ms})$ in comparison to those containing singular non-heads $(38 \mathrm{~ms})\left(t_{1}(27)=2.73\right.$, p $\left.=.011 ; t_{2}(34)=2.88, \mathrm{p}=.007\right)$, and also for head nouns of compounds containing irregular plurals $(57 \mathrm{~ms})$ in comparison to those containing singular non-heads $(38 \mathrm{~ms})\left(t_{1}(27)=2.42\right.$, p $\left.=.023 ; t_{2}(34)=1.79, \mathrm{p}=.082\right)$. No significant differences were obtained for the rereading time of head nouns of compounds containing regular plurals (60ms) in comparison to those containing irregular plurals (57ms) $\left(t_{1}(27)<1, \mathrm{p}=.740 ; t_{2}(34)<1, \mathrm{p}=.658\right)$.

Finally, a one-way ANOVA revealed a significant main effect of non-head type on the total viewing time data $\left(F_{1}(2,54)=15.18, \mathrm{p}<.001 ; F_{2}(2,51)=7.11, \mathrm{p}=.002\right)$, and subsequent pairwise comparisons revealed significant differences between all conditions. Head nouns of compounds containing regular plurals had a significantly longer total viewing time (339ms) than both head nouns of compounds containing irregular plurals (307ms) $\left(t_{1}(27)=2.90, \mathrm{p}=.007 ; t_{2}(34)=2.24, \mathrm{p}=.032\right)$ and those containing singular non-heads (282ms) $\left(t_{1}(27)=5.17, \mathrm{p}<.001, t_{2}(34)=3.71, \mathrm{p}=.001\right)$. The total viewing time for head nouns of compounds containing irregular plurals (307ms) was also significantly longer than for head nouns of compounds containing singular non-heads $(282 \mathrm{~ms})\left(t_{1}(27)=2.81, \mathrm{p}=\right.$ $\left..009 ; t_{2}(34)=1.51, \mathrm{p}=.140\right)$.

The effects on the reading times of the head noun can be summarized in three points. First, the earliest measures of first-pass processing (first fixation duration/gaze duration) revealed longer reading times for head nouns of compounds containing regular plurals than for those containing irregular plurals or singular non-heads, with no differences between 
irregular and singular non-heads. Second, the processing measure that specifically excludes the initial time spent in a region (rereading time) and instead taps second-pass processing revealed longer reading times for head nouns of compounds containing plurals (regardless of regularity) in comparison to those containing singular non-heads. Finally, the two measures (regression path duration, total viewing time) that included both the initial time spent in the region and any extra processing time incurred after this initial inspection, revealed a gradual pattern of responses consistent with the results of Experiment 1, with relatively short reading times for head nouns of compounds containing singular non-heads, followed by longer reading times for head nouns of compounds containing irregular plural non-heads, with head nouns of compounds containing regular plural non-heads producing the longest reading times.

\section{Additional analyses}

The first additional analysis was motivated by the possibility that, due to parafoveal processing of the head noun, differences between the experimental conditions might already occur on the first-pass reading times of the non-head elements of the compounds. To assess this possibility, we calculated the two earliest reading time measures (first fixation duration, gaze duration) as well as the slightly later regression path measure for the non-head nouns in the three experimental conditions. As the non-heads used were generally quite short, the nonhead region was defined as the non-head noun and the word preceding (always a definite determiner), plus half a letter space either side. This region received a progressive first fixation in $91.16 \%, 91.49 \%$ and $88.44 \%$ of trials in the irregular plural, regular plural and singular conditions respectively. This amounted to an overall first-pass fixation probability of $90.46 \%$, with no significant differences between conditions $\left(F_{1}(2,54)=2.21, \mathrm{p}=.119\right.$; $\left.F_{2}(2,51)=1.58, \mathrm{p}=.216\right)$ 
Regarding the first fixation duration of the non-head region of the compound, the mean values for the irregular plural, regular plural and singular conditions were 231ms, 229ms and 231ms respectively, with no significant differences between conditions $\left(F_{1}(2,54)<1, \mathrm{p}=\right.$ $\left..676 ; F_{2}(2,51)<1, p=.587\right)$. With regards to gaze duration, the mean values for the irregular plural, regular plural and singular conditions were 286ms, 283ms and 284ms respectively, again with no significant differences between conditions $\left(F_{1}(2,54)<1\right.$, p $=$ $\left..941 ; F_{2}(2,51)<1, \mathrm{p}=.975\right)$. Finally, the regression path duration was 336ms, 361ms and 358ms for the irregular plural, regular plural and singular conditions respectively. Whilst the regression path duration of the irregular plural non-heads are numerically shorter than for the other two conditions, a one-way ANOVA did not reveal any significant differences between conditions $\left(F_{1}(2,54)=1.377, \mathrm{p}=.261 ; F_{2}(2,51)<1, \mathrm{p}=.592\right)$. Taken together, these results indicate that the experimental manipulation did not affect the first-pass reading times of the non-head nouns.

The purpose of the second additional analysis was to determine potential spill-over effects of the experimental manipulations after leaving the target word. We calculated the duration of the first fixation after the head noun had been exited for the first time. The mean duration of this fixation was $227 \mathrm{~ms}$, 243ms and 226ms for the irregular plural, regular plural and singular conditions respectively, and a one-way ANOVA revealed a significant main effect of non-head type $\left(F_{1}(2,54)=5.91, \mathrm{p}=.005 ; F_{2}(2,51)=3.96, \mathrm{p}=.026\right)$. Subsequent pairwise comparisons revealed that, whilst the duration of the first fixation upon leaving the head noun was significantly longer for compounds containing regular plurals in comparison to those containing singular non-heads $\left(t_{1}(27)=2.98, \mathrm{p}=.006, t_{2}(34)=2.26, \mathrm{p}=.031\right)$ and in comparison to those containing irregular plural non-heads $\left(t_{1}(27)=2.67, \mathrm{p}=.013, t_{2}(34)=\right.$ 2.30, $\mathrm{p}=.028$ ), no significant differences were found between the duration of the first fixation upon leaving the head noun for compounds containing irregular plurals in 
comparison to those containing singular non-heads $\left(t_{1}(27)<1, \mathrm{p}=.801, t_{2}(34)<1, \mathrm{p}=.960\right)$. These results indicate a reliable spill-over effect for the regular plural condition.

\section{Discussion}

Both experiments revealed a preference for singular non-heads inside compounds, evidenced by higher acceptability ratings and shorter rereading and total viewing times for head nouns of compounds containing singular non-heads than those containing plural nonheads. This preference results from a constraint against plural NUMBER semantics on compound-internal modifiers. This constraint, however, does not seem to be operative at early stages of processing, as is clear from Experiment 2 in which the two earliest first-pass measures of processing did not reveal any differences between head nouns of compounds with irregular plural versus singular non-heads. Another finding from both experiments is that regular plural non-heads are dispreferred inside compounds relative to irregular plural or singular non-heads; compounds with regular plurals yielded the lowest acceptability ratings and the longest first fixation and gaze durations. We argued that these contrasts result from a morphological constraint that prevents rule-based inflected words (e.g. [[rat]+s]), but not memorized lexical items (e.g. [mice]), to enter the formation of a lexical compound. Crucially, effects of this constraint were found during the earliest measures of processing in Experiment 2, indicating that the morphological constraint becomes available earlier than the semantic one during the processing of a compound. Finally, reliable spill-over effects were only found for compounds containing regular plural non-heads, indicating that whilst violations of the morphological constraint continued to disrupt processing for some time after leaving the head noun region, disruption caused by violations of the semantic constraint were more short lived. 
Recall that Haskell et al. (2003) argued that speakers' dislike of regular plurals inside compounds is due to the phonological form of the non-head element. From this perspective, the results of Experiment 2 could be taken to indicate that phonological information becomes available before semantic information during compound processing. We pointed out, however, that the idea of interpreting the plurals-in-compounds effect in phonological terms is problematic in a number of ways and maintained that the constraint against regular plurals is morphological in nature.

In the introduction, we mentioned two models of the time course of language processing. The structure-first account predicts that morpho-syntactic information is available at the earliest stages of processing whereas semantic and discourse-level information only affect later stages of processing. Given that the use of regular plurals inside compounds is structurally constrained (by a distinction among kinds of morphological forms), the structure-first hypothesis rules out regular plurals as potential non-heads inside compounds from the earliest stages of processing, while at the same time allowing both irregular plurals and singulars. Thus, compounds with regular plurals should yield increased processing times relative to those with irregular plurals and singulars, from the earliest measures of first-pass processing. The semantic constraint against non-heads with [+plural] NUMBER semantics, on the other hand, should not affect early stages of processing, hence early processing measures should not be sensitive to whether the non-head is an irregular plural or a singular noun. Our results are compatible with these predictions indicating that the morphological constraint has an immediate effect on compound processing, whilst effects of the semantic constraint are seen later. More specifically we suggest that compound processing involves two stages, an initial stage at which the compound is decomposed into its morphological constituents (i.e. head and non-head), and a later stage at which the head noun is semantically integrated with the non-head to form a fully specified compound 
meaning. Given this distinction, the elevated first fixation and gaze duration for head nouns of compounds containing regular plural non-heads can be taken to index the detection of a structural anomaly during the initial stage of morphological parsing. Violations of plural NUMBER semantics, on the other hand, appear to be detected at the later semantic integration stage, as indicated by the longer regression path duration and longer rereading time for head nouns of compounds in the two plural conditions in comparison to the singular condition.

As an alternative, we considered a parallel-constraints view of compound processing, according to which the language processor makes use of all relevant constraints in a parallel, competition process from the earliest stages of processing. The clearest support for this view would come from the finding that the different compounding constraints apply in tandem throughout processing and produce a gradual pattern of responses depending on how many constraints are violated. Compounds containing regular plurals should yield the longest reading times (because they violate more than one constraint), followed by compounds containing irregular plural non-heads (which only violate the semantic constraint), while compounds containing singular non-heads should produce the shortest responses (because they do not violate any constraint). We obtained this pattern of results for eye-movement measures that are sensitive to late stages of processing, but not for early measures of processing. Thus, it was not the case that different kinds of constraints affected the processing of compounds equally early. We believe that these findings impose clear constraints on theories of compound processing and are consistent with the view that structural (morphological) information becomes available earlier than semantic information during on-line processing. 


\section{Acknowledgements}

Supported by an ESRC postgraduate training scholarship. We are grateful to Keith Rayner, one additional anonymous Cognition reviewer, and the members of the Psycholinguistics Research Group at our department for comments and helpful discussion. 


\section{References}

Altmann, G., Garnham, A., \& Dennis, Y. (1992). Avoiding the garden path: Eye movements in context. Journal of Memory and Language, 31, 685-712.

Andrews, S., Miller, B. \& Rayner, K. (2004). Eye movements and morphological segmentation of compound words: There is a mouse in mouse trap. European Journal of Cognitive Psychology, 16, 285-311.

Aronoff, M. (1976). Word Formation in Generative Grammar. Cambridge, MA: MIT Press.

Baayen, H., Piepenbrock, R. \& van Rijn, H. (1993). The CELEX lexical database (CD ROM). Philadelphia, PE: Linguistic Data Consortium, University of Pennsylvania.

Berent, I., Pinker, S., Ghavami, G. \& Murphy, S. (under review). The dislike of regular plurals in compounds: Phonological familiarity or morphological constraint? Unpublished Manuscript.

Bertram, R. \& Hyönä, J. (2003). The length of a complex word modifies the role of morphological structure: Evidence from eye movements when reading short and long Finnish compounds. Journal of Memory and Language, 48, 614-634.

Bertram, R. Pollatsek, A. \& Hyönä, J. (2004). Morphological parsing and the use of segmentation cues in reading Finnish compounds. Journal of Memory and Language, 51, 325-345

Binder, K., Duffy S. \& Rayner, K. (2001). The effects of thematic fit and discourse context on syntactic ambiguity resolution. Journal of Memory and Language, 44, 297-324.

Bock, K. \& Eberhard, K. (1993). Meaning, sound, and syntax in English number agreement. Language and Cognitive Processes, 8, 57-99.

Bock, K., Eberhard, K., Cutting, J., Meyer, A. \& Schriefers, H. (2001). Some attractions of verb agreement. Cognitive Psychology, 43, 83-128. 
Buck-Gengler, C., Menn, L. \& Healy, A. (2004). What 'mice trap' tells us about the mental lexicon. Brain and Language, 90, 453-464.

Borer, H. (1988). On the parallelism between compounds and constructs. Yearbook of Morphology, 1, 45-66.

Clahsen, H. (1999). Lexical entries and rules of language: a multi-disciplinary study of German inflection. Behavioral and Brain Sciences 22: 991-1013.

Di Sciullo, A., and Williams, E. (1987). On the Definition of Word. Cambridge, MA: MIT Press.

Frazier, L. \& Clifton, C. (1996). Construal. Cambridge, MA: MIT Press.

Frazier, L. \& Fodor, J. D. (1978). The sausage machine: A two-stage parsing model. Cognition, 6, 291-325.

Gordon, P. (1985). Level-ordering in lexical development. Cognition, 21, 73-93.

Haskell, T., MacDonald, M. \& Seidenberg, M. (2003). Language learning and innateness: Some implications of compounds research. Cognitive Psychology, 47, 119-163.

Hyönä, J. \& Pollatsek, A. (1998). Reading Finnish compound words: Eye fixations are affected by component morphemes. Journal of Experimental Psychology: Human Perception and Performance, 24, 1612-1627.

Hyönä, J. Bertram, R. \& Pollatsek, A. (2004). Are long compound words identified serially by their constituents? Evidence form an eye-movement contingent display change study. Memory and Cognition, 32, 523-532.

Inhoff, A., Radach, R. \& Heller, D. (2000). Complex compounds in German: Interword spaces facilitate segmentation but hinder assignment of meaning. Journal of Memory and Language, 42, 23-50.

Juhasz, B. J., Inhoff, A. \& Rayner (2005). The role of interword spaces in the processing of English compound words. Language and Cognitive Processes, 20, 291-316. 
Juhasz, B. J., Starr, M. S., Inhoff, A. \& Placke, L. (2003). The effects of morphology on the processing of compound words: Evidence from lexical decision, naming and eye fixations. British Journal of Psychology, 94, 223-244.

Kiparsky, P (1982). From cyclic phonology to lexical phonology. In van der Hulst, H. \& Smith, N. (eds.), The Structure of Phonological Representations (Part 1), Dordrecht: Foris.

McElree, B. \& Griffith, T. (1998). Structural and lexical constraints on filling gaps during sentence comprehension: A time-course analysis. Journal of Experimental Psychology: Learning, Memory, and Cognition, 24, 432-460.

Murphy, V. (2000). Compounding and the representation of L2 inflectional morphology. Language Learning, 50, 153-197.

Pinker, S. (1999). Words and rules. Basic Books: New York.

Pollatsek, A. \& Hyönä, J. (2005). The role of semantic transparency in the processing of Finnish compound words. Language and Cognitive Processes, 20, 261-290.

Pollatsek, A., Hyönä, J. \& Bertram, R. 2000. The role of morphological constituents in reading Finnish compound words. Journal of Experimental Psychology: Human Perception and Performance, 26, 820-833.

Rayner, K., (1998). Eye movements in reading and information processing: 20 years of research. Psychological Bulletin, 124, 372-422.

Rayner, K. Carlson, M. \& Frazier, L. (1983). The interaction of syntax and semantics during sentence processing: Eye movements in the analysis of semantically biased sentences. Journal of Verbal Learning and Verbal Behavior, 22, 358-374.

Rayner, K., Warren, T., Juhasz, B. \& Liversedge, S. (2004). The effect of plausibility on eye movements in reading. Journal of Experimental Psychology: Learning, Memory and Cognition, 6, 1290-1301. 
Rayner, K., \& Pollatsek, A. (1989). The Psychology of Reading. New Jersey, Prentice Hall.

Senghas, A., Kim, J. \& Pinker, S. (under review). The plurals-in-compounds effect. Unpublished Manuscript.

Sonnenstuhl, I. \& Huth, A. (2002). Processing and representation of German -n plurals: A dual mechanism approach. Brain \& Language, 81, 276-290.

Spivey, M. J, Fitneva, S. A., Tabor, W. \& Ajmani, S. (2002). The time course of information integration in sentence processing. In Merlo, P. \& Stevenson, S. (eds.), The Lexical Basis of Sentence Processing. Amsterdam: John Benjamins.

Sturt, P. (2003). The time-course of the application of binding constraints in reference resolution. Journal of Memory and Language 48, 542-562.

Thornton, R., Gil, M., \& MacDonald, M.C. (1998). Accounting for cross-linguistic variation: A constraint-based perspective. In Hillert, D (ed.), Syntax and Semantics Vol. 31: A Crosslinguistic Perspective, San Diego, Academic Press.

van der Lely, H. \& Christian, V. (2000). Lexical word formation in children with grammatical SLI: A grammar-specific versus an input-processing deficit? Cognition, 75, 33-63. 
Table 1: Mean acceptability ratings (and standard deviations) for compounds in three experimental conditions

Condition

Irregular Plural $\quad$ Regular Plural Singular

$3.9(.95) \quad 2.8(.93) \quad 5.4(.88)$ 
Table 2: $\quad$ Mean durations (and standard deviations) of five eye-tracking measures (in msec.) for the head noun region in three experimental conditions Irregular Plural Regular Plural Singular

\begin{tabular}{lccc} 
First Fixation Duration & $227(28)$ & $243(35)$ & $221(32)$ \\
Gaze Duration & $250(46)$ & $279(51)$ & $244(40)$ \\
Regression Path Duration & $325(85)$ & $362(82)$ & $291(62)$ \\
Re-Reading Time & $57(39)$ & $60(36)$ & $38(28)$ \\
Total Viewing Time & $307(61)$ & $339(66)$ & $282(48)$ \\
\hline
\end{tabular}


Appendix A: Frequencies and length of non-head nouns used in Experiments 1 and 2

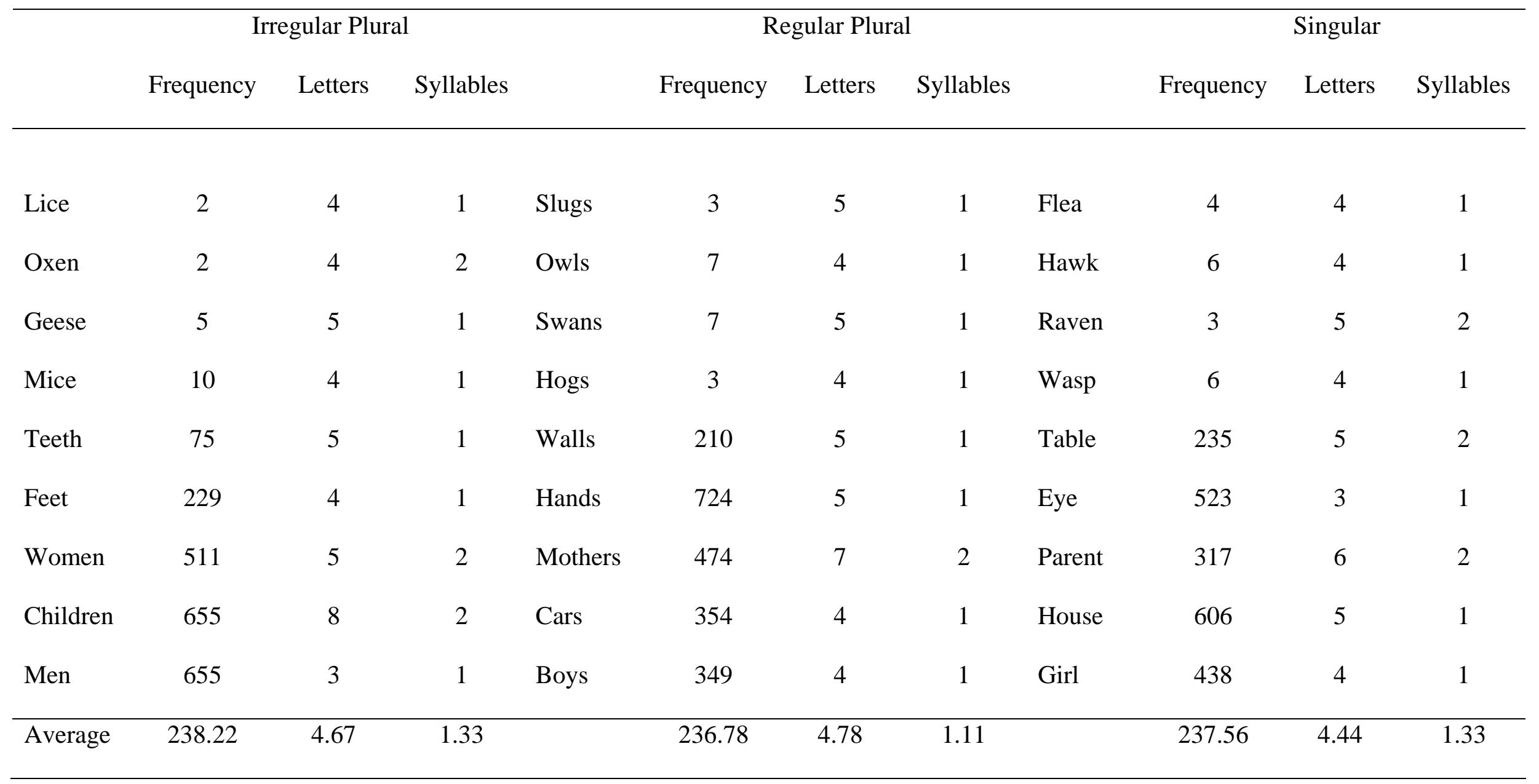


Appendix B: Non-head and head noun combinations in Experiments 1 and 2

Non-Head Head 1

Head 2

Lice/Slugs/Flea

Oxen/Owls/Hawk

Geese/Swans/Raven

Mice/Hogs/Wasp

Teeth/Walls/Table

Feet/Hands/Eye

Women/Mothers/Parent

Children/Cars/House

Men/Boys/Girl
Remover

Breeder

Keeper

Lover

Cleaner

Examiner

Watcher

Lover

Watcher
Eradicator

Seller

Feeder

Trader

Washer

Protector

Admirer

Protector

Eater 